\title{
Peróxido de hidrogênio como agente despirogenizante de componentes para produtos médico-hospitalares
}

\author{
Hydrogen peroxide as depyrogenation agent for medical \\ devices components
}

\author{
Terezinha de Jesus A.Pinto \\ Departamento de Farmácia da Faculdade de Ciências Farmacéuticas \\ da Universidade de São Paulo - Brasit.
}

\begin{abstract}
A atual busca de solventes alternativos aos fluorados, frente ao problema de depleçåo de ozônio da estratosfera, obriga a desenvolvimentos de processos apllcáveis á fabricação de produtos médlco-hospitalares. Frente ao desafio, e considerando a água estar sendo opçāo de escolha de outros segmentos industriais, preocupa a rápida prollferaçăo microbiana na mesma, tornando-a fonte potencial de endotoxinas. Tal risco incompatibiliza-se por exemplo, com a produção de itens destinados ao emprego em procedimentos cirúrgicos da área cardiovascular. Desta forma foi rajizada pesquisa com o objetivo de investigar possibilidade de emprego da água como agente de limpeza de componentes para tais produtos, desde que incorporada de peróxido de hidrogènio. Trabalhou-se inoculando água e soluçōes de peróxido com niveis de $0,1,0,25,0,5$ ө1,0 UE/ml; obteve-se a confirmação de efetividade de açăo a concentraçāo de $5 \%$ de peróxido de hidrogênio, através de determinação analítlca pelo método "in vitro". Investigouse, em peças injetadas em policarbonato, destinadas a fabricação de oxigenadores e reservatórlos sangúíneos, inoculadas com endotoxina, a efetividade no uso do peróxido. Os resultados permitem concluir pela possibilidade de sucesso do processo proposto, seja pelo aspecto biológico ou pela remoçāo de sujidades.
\end{abstract}

Peróxido de hidrogênio. Endotoxinas. Pirogênios. Contaminação de equipamentos, prevençăo \& controle.

\section{Introdução}

Assim como na indústria eletrônica, naquela de artigos médico-hospitalares, empregando essencialmente matéria-prima polimérica, considera-se essencial a lavagem dos componentes injetados, anteriormente à montagem dos mesmos em ambientes limpos.

$O$ solvente ideal para tal lavagem tem sido $o$ clorofluorcarbono, particularmente o freon 12. Isto devido às características físico-químicas, principalmente pela sua inércia química frente ao material polimérico além de atoxicidade. Entretanto, frente ao impacto causado pelo conhecimento da depleção de ozônio na estratosfera e ao visar obediência ao protocolo de Montreal se buscam alternativas, ainda que menos eficientes no aspecto técnico. Um substituinte bem sucedido, encontrado pela indústria eletrônica, foi a água.
$\mathrm{Na}$ área médico-hospitalar, o desafio existe particularmente envolvendo produtos destinados à área cardiopulmonar como o oxigenador sangüíneo. Este por apresentar, no geral, grande dimensão e seu uso representar elevado risco ao paciente ${ }^{5, x}$, impõe preocupaçāo adicional àquela área. A demanda de grande volume de água destilada para enxagüe das peças induz ao seu armazenamento, o que acarreta a preocupação quanto à contaminação pirogênica ${ }^{1,1 s}$. Também a permanência de gotículas de água aderidas ao componente até sua secagem completa pode comprometer a qualidade do produto com a mesma questāo. A proliferaçāo de bactérias gram-negativas na água destilada origina elevada carga de endotoxinas, responsável pela pirogenicidade ${ }^{15}$. Ainda, o caráter termolábil dos componentes em questão afasta a aplicaçāo dos métodos convencionais de destruição das endotoxinas ${ }^{4,9}$. Deve-se buscar outros 
recursos para sua remoção ou inativação. A perspectiva de inativação de endotoxinas por peróxido de hidrogênio motivou o presente estudo, levando em consideração o processo oxidativo sem permanência do proprio agente oxidante.

\section{Material e Método}

\section{Material}

Foi empregado como substrato polimérico o policarbonato, que submetido ao processo de moldagem por injeção permite testar 2 tipos de peças: o primeiro (A) de conformaçāo geométrica correspondente ao cilindro do Oxigenador Sangüíneo, com área total de $1.188 \mathrm{~cm}^{2}$, o segundo (B), de conformação parcialmente cilíndrica terminando em calota esférica, com área total de $1.164 \mathrm{~cm}^{2}$, sendo componente empregado na fabricaçāo de Reservatório de Cardiotomia. A amostragem foi de 27 unidades de cada tipo.

A endotoxina de Escherichia coli 055:135 foi adquirida no comércio local sob forma liofilizada, e quando reconstituída em $5,0 \mathrm{ml}$ de água apirogênica apresentava o teor de $2 \mathrm{ng} / \mathrm{ml}$. $\mathrm{O}$ reagente para deteç̧ão de endotoxinas na forma liofilizada, com sensibilidade igual a $0,06 \mathrm{UE} / \mathrm{ml}$, foi adquirido do mesmo fornecedor daquela. $O$ peróxido de hidrogênio, P.A, a $32 \%$ (v/v) serviu como agente oxidante.

\section{Método}

\section{Método de Contaminaçāo por Endotoxinas}

Assepticamente, as peças de ambos tipos, comprovadamente apirogênicas, foram contaminadas através de $1 \mathrm{ml}$ de água destilada contendo quantidades conhecidas de endotoxinas, cuja alíquota foi espalhada na superficie interna. Assim, 15 unidades, tanto de $\mathrm{A}$ como $\mathrm{B}$, receberam 2,0 UE por peça, enquanto $1,0,0,5$ e $0,25 \mathrm{UE}$ foram aplicadas para téplica de 3 peças, igualmente para ambos tipos. As peças contaminadas foram mantidas em capelas de fluxo laminar até secagem completa da água destilada.

\section{Processamento Oxidativo das Amostras Contaminadas}

Doze das 15 unidades, tanto do tipo A como do B, contaminadas com 2,0 UE foram lavadas com solução aquosa de detergente Vetec, $a 3 \% \mathrm{v} / \mathrm{v}$, mantendo-as imersas durante 5 minutos em 8 litros contidos em cuba plástica,

$O$ tratamento subseqüente foi a imersão de cada réplica de 3 peças, de ambos tipos durante 5 min, em 8 litros de solução aquosa de peróxido de hidrogênio nas concentrações de 1,0, 2,0 e 5,0\% (v/v). A repetição seqüencial do banho em 3 outras cubas foi em idênticas condições, respeitando o mesmo tratamento oxidativo, completando 4 banhos em série, para cađa concentração de peróxido de hidrogênio.

\section{Comprovação de Interação entre Peróxido de Hidrogênio e Endotoxina}

Cinqüenta $\mathrm{ml}$ de peróxido de hidrogênio a $1,0,2,0$ e $5,0 \%$ foram contaminados com endotoxina a fim de obter $0,10,0,25,0,50$ e 1,00 $\mathrm{UE} / \mathrm{mL}$ e estas misturas foram mantidas a temperatura de $22+1-2^{\circ} \mathrm{C}$ durante 2 horas e submetidas à reação de gelificação, em comparação à solução aquosa de endotoxina padrăo.

\section{Avaliação das Amostras após Tratamento com Peróxido de Hidrogênio}

A superfície interna das peças foi submetida ao processo extrativo da endotoxina através de contato de $10 \mathrm{ml}$ de água destilada livre de endotoxinas, com agitação manual durante 15 min. Cada extrato foi analisado quanto à reação positiva ou negativa de gelificação.

\section{Validação do Processo Extrativo}

As amostras contaminadas com diferentes quantidades de endotoxina e que não foram tratadas com detergente e água oxigenada foram igualmente extraídas com água destilada e submetidas à reação de gelificação.

\section{Reaçāo de Gelificação}

O procedimento analítico foi segundo USP $\mathrm{XXI}$, usando reagente $\mathrm{LAL}^{17}$; considerou-se como controle positivo a concentração de $0,125 \mathrm{UE} / \mathrm{ml}$.

\section{Influência da Lavagem das Peças com Detergente}

De cada tipo de peças, separadas em funçāo do tratamento ou não com detergente, foram reunidos $40 \mathrm{ml}$ a partir dos extratos de 12 e 9 unidades, respectivamente, independente do teor contaminante de endotoxinas. Estas alíquotas foram filtradas pela membrana celulósica de 0,45 
$\mathrm{mm}$ e $55 \mathrm{~mm}$ de diâmetro e observadas em microscópio óptico $(400 \mathrm{x})$ quanto à presença de partŕculas ou pontos translúcidos.

\section{Resultados}

Os resultados obtidos para confirmação da capacidade inativante do peróxido de hidrogênio estão descritos na Tabela 1.

Dados das Tabelas 2 e 3 mostram resultados de presença de endotoxinas em peças do típo $\mathrm{A} \mathrm{e}$ $B$, apenas inoculadas (Tabela 2) e submetidas a tratamento após inoculação (Tabela 3). A Tabela 4 expressa os resultados quanto a presença de sujidades, em extratos obtidos de peças submetidas ou nāo ao procedimento de lavagem proposto.

\section{Discussão}

Entre as várias e possíveis fontes de endotoxinas, particularmente envolvendo procedimentos cirúrgicos cardíacos, estão os componentes de circulaçāo extracorpórea, soluções de infusāo, material cirúrgico e auto-contaminaçāo por bactérias gram-negativas do trato intestinal ${ }^{13}$.

Atendo-se particularmente aos componentes de circulação extracorpórea contemplados pelos componentes poliméricos de escolha para o presente trabalho, deve-se salientar a afinidade entre endotoxinas e material plástico, relatada por Sawada e col. ${ }^{4}$, embora discordante dos dados obtidos por Roslansky e col. ${ }^{12}$ para polipropileno e poliestireno. Associando ao conhecimento expresso por Nilsson e col. ${ }^{11}$, que enfatizam a importância da análise de endotoxinas ligadas à superfície polimérica, que ainda assim induzem a reaçōes de ativação do complemento, justifica atençāo particular a este segmento, buscando a garantia na liberaçāo destes correlatos livres da presença de endotoxinas.

Tabela 1. Comprovaçäo da capacidade inativante de peróxido de hidrogênlo em diferentes concentraçōes de endotoxinas de Escherichia coll.

\begin{tabular}{ccccc}
\hline $\mathrm{H}_{2} \mathrm{O}_{2}$ & \multicolumn{4}{c}{ Endotoxina (UE/ml) } \\
$(\% \mathrm{VV} / \mathrm{V})$ & 1,00 & 0,50 & 0,25 & 0,10 \\
\hline 0 & $(+)(+)$ & $(+)(+)$ & $(+)(+)$ & $(+)(+)$ \\
1,0 & $(+)(+)$ & $(+)(+)$ & $(+)(+)$ & $(+)(-)$ \\
2,0 & $(+)(-)$ & $(-)(-)$ & $(-)(-)$ & $(-)(-)$ \\
5,0 & $(-)(-)$ & $(-)(-)$ & $(-)(-)$ & $(-)(-)$ \\
\hline
\end{tabular}

$(+)=$ resposta positiva de gelificação a partir de 0,125 $\mathrm{UE} / \mathrm{ml}$ do padräo.

$(-)=$ resposta negativa de gelificaçăo a partir de 0,125 $\mathrm{UE} / \mathrm{ml}$.
Tabela 2. Avaliaçāo da técnica extrativa de endotoxinas, previamente inoculadas em amostras de ambos tipos.

\begin{tabular}{cccccc}
\hline \multirow{2}{*}{ Amostra } & \multicolumn{5}{c}{ Endotoxina inoculada (UE/Peça) } \\
& 2,00 & 1,00 & 0,50 & 0,25 & 0 \\
\hline A & $(+)(+)$ & $(+)(+)$ & $(-)(-)$ & $(-)(-)$ & $(-)(-)$ \\
& $(+)(+)$ & $(+)(-)$ & $(-)(-)$ & $(-)(-)$ & $(-)(-)$ \\
& $(+)(+)$ & $(+)(-)$ & $(-)(-)$ & $(-)(-)$ & $(-)(-)$ \\
B & $(+)(+)$ & $(+)(\cdot)$ & $(-)(\cdot)$ & $(-)(-)$ & $(-)(-)$ \\
& $(+)(+)$ & $(+)(+)$ & $(-)(\cdot)$ & $(\cdot)(-)$ & $(\cdot)(-)$ \\
& $(+)(+)$ & $(+)(+)$ & $(-)(\cdot)$ & $(-)(-)$ & $(\cdot)(\cdot)$ \\
\hline
\end{tabular}

$(+)=$ resposta positiva de gelificaçăo a partir de 0,125 $\mathrm{UE} / \mathrm{m} \mid$.

$(-)=$ resposta negativa de gelificaçäo a partir de 0,125 $\mathrm{UE} / \mathrm{ml}$.

$\mathrm{A}=$ cilindro de Oxigenador SangüIneo.

$\mathrm{B}=$ calota esférica de Reservatório de Cardiotomia.

O peróxido de hidrogênio foi há muitos anos considerado efetivo na destruição de endotoxinas, dependendo de concentração, tempo đe contato e temperatura ${ }^{2,10,16}$, embora sem elucidação completa do mecanismo da reação ${ }^{3,6,7}$. Na aplicação proposta inexistem riscos de incompatibilidade, sendo resíduo único a umidade, eliminada quando da secagem final dos componentes. A presente proposta nāo é de eliminaçāo de altos teores de endotoxina contaminante de material reciclado, e sim prevenir que níveis reduzidos envolvidos no ciclo produtivo permaneçam nos produtos oferecendo risco ao paciente.

Pelos dados da Tabela 1 pode-se dizer que a inativaçāo da endotoxina é total frente a $5 \%$ de peróxido de hidrogênio; entretanto, mesmo a $2 \%$ níveis da ordem de $0,5 \mathrm{UE} / \mathrm{mI}$ apresentam resposta negativa à gelificaçāo com parâmetro analítico correspondente a inversão dos tubos de $180^{\circ}$, fato comprovado com $0,1 \mathrm{UE} / \mathrm{ml}$ do padrāo. Neste ensaio foi testada a concentração de

Tabela 3. Determ/naçåo de endotoxinas em axtratos de amostras inoculadas com $2 U E$ e submetidas ao processo oxidativo.

\begin{tabular}{ccccc}
\hline \multirow{2}{*}{ Amostra } & 0 & $\mathrm{H}_{2} \mathrm{O}_{2}(\%$ v/v) & \\
& 0 & 1 & 2 & 5 \\
\hline A & $(+)(+)$ & $(+)(-)$ & $(-)(-)$ & $(-)(-)$ \\
& $(+)(+)$ & $(+)(-)$ & $(+)(-)$ & $(-)(-)$ \\
& $(+)(+)$ & $(-)(-)$ & $(-)(-)$ & $(-)(-)$ \\
B & $(+)(+)$ & $(+)(-)$ & $(-)(\cdot)$ & $(-)(-)$ \\
& $(+)(+)$ & $(+)(-)$ & $(+)(-)$ & $(-)(-)$ \\
& $(+)(+)$ & $(+)(-)$ & $(+)(-)$ & $(-)(-)$ \\
\hline
\end{tabular}

$(+)=$ resposta positiva correspondente a partir de 0,125 $\mathrm{UE} / \mathrm{ml}$.

$(-)=$ resposta negativa de gelificaçäo a partir de 0,125 $\mathrm{UE} / \mathrm{ml}$.

$A=$ cilindro de Oxigenador Sangüineo.

$\mathrm{B}=$ calota esférica de Reservatório de Cardlotomia. 
Tabela 4. Avaliação comparativa de peças lavadas e nåo lavadas quanto à sujidade após filtração.

\begin{tabular}{ccc}
\hline Amostra & $\begin{array}{c}N^{2} \text { de pontos } \\
\text { translúcidos na membrana } \\
\text { filtrante }\end{array}$ & $\begin{array}{c}N^{2} \text { de particulas } \\
\text { na membrana } \\
\text { filtrante }\end{array}$ \\
\hline A & 0 & 0 \\
B & 0 & 22 \\
& 0 & 0 \\
\hline
\end{tabular}

$A=$ cilindro de Oxigenador Sangŭineo.

$\mathrm{B}=$ calota esférica de Reservatório de Cardiotomia.

até 1,0 UE/ml, apesar de níveis de "pyroburden" esperados em processo industrial não ultrapassar tal ordem.

Quanto à técnica extrativa de endotoxinas inoculadas as amostras houve, evidentemente, preocupação para este fato, uma vez que diferentes autores salientam sobre a afinidade entre superfície polimérica e molécula de LPS. Ao lado disto, a conformaçāo e dimensāo das amostras em questảo acarretaram limitações de ordem mecânica, o que provocou freqüência de resposta positiva de 7/12 (Tabela 2). Assim, seguramente a resposta positiva para gelificação com inversão dos tubos está significando extração de endotoxinas igual ou maior que $0,125 \mathrm{UE} / \mathrm{ml}$.

Quando se procura relacionar esta constataçāo com os dados da Tabela 3, em que peças contendo 2,0 UE foram submetidas à extração após a interação com peróxido de hidrogênio, a 3 diferentes concentraçōes, pode-se dizer que a $5 \%$ a situação é equivalente no máximo à condiçāo de $0,5 \mathrm{UE} /$ peça da Tabela 2, ou seja, 0,05 UE/ml.

Outro aspecto de qualidade destes produtos com vistas à segurança do paciente diz respeito às partículas, de um modo geral, assim como presença de material graxo resultante do processo de moldagem. Quando se efetuou a comparação entre os 2 grupos, os extratos filtrados após o tratamento com tensoativo apresentaram nível inferior em relação a estes contaminantes (Tabela 4).

Diante destes dados restaram detalhamentos para adaptação industrial do processo na linha de produção de equipamento médico-hospitalares, particularmente para a área cardiovascular.

\section{Conclusões}

É possível a substituição de solventes clorofluorados por aquosos na lavagem de componentes destinados a emprego na área médicohospitalar. Para tanto, monitoração da carga inicial e final de endotoxina, assim como aspectos físicos devem ser controlados.

O peróxido de hidrogênio mostra-se efetivo na reduçāo de teores de endotoxina de Escherichia coli em soluçōes aquosas.

\section{Referências Blbliograficas}

1. AVALLONE, H.L. Control aspects of aseptically produced produets, J. Parent. Sci. Technol, 39:75-9, 1985.

2. CAMPBELL,D.H.\&CHERKIN,A.Thedestruction of pyrogens by hydrogen peroxide. Science, 102: 535-6, 1945.

3. CASE,M,J. \& NOVITSKY,T.J. Depyrogenation by hydrogen peroxide. P.D.A. Monograph on depyrogetration, in: Pearson, F. C. Pyrogens: endotoxins, LALlesting, and depyrogenation. New York, MARCEL DEKKER Inc., p. 203-J4, 1985.

4. CRAVERI, A.; BERTINETTI, M.; MONTEVECCHI, F.M.; TASSARA, A.; TAGLIAPIETRA, L.L'utilizzo del computer per la quantificazione dell' $F$ HeF T nel trattamento di degermazione e di depirogenazione con il calore secco. Boll. Chim. Farm.,125: 85-92, 1986.

5. DANNER, R.L.; NATANSON, C.: ELEN,R.J.: HOSSEINIJ.M.; BANK, S; MAC VITTIE, T. J.; PARRILLO, J. E. Pseudomonas aeruginosa cornpared with Escherichia coli produces less endotoxemia but more cardiovascular dysfunction and mortality in a canine model of septic shock. Chest, 98: 1480-7, 1990.

6. DE RENZIS, F, A. Endotoxina - inactivating potency of molecular oxygen: effect on cell growth. J. Dent.Res, 59:1521, 1980.
7. DE RENZIS, F. A. Endotoxina - inactivating potency of hydrogen peroxide: effect on cell growth. J. Dent. Res., 60: 933-5, 1981.

8. LONNERNANN, G. Dialysate bacteriological quality and the permeability of dialyzer membranes to pyrogens. Kidney Int, 43:195-200, 1993.

9. MASCOLI, C.C. \& WEARY, M.E. Limulus amebocyte lisate (LAL) test for detecting pyrogens in parenteral injectable products and medical devices: advantiges to manufactures and regulatory officials. $J$, Parent.Drug Assoc., 33: 81-95, 1979.

10. MENCZEL. E. A note on the depyrogenation of infusion solutions by hydrogen peroxide. J. Am. Pharm. Assoc., 40:175-6, 1951

11. NILSSON,L.; KULANDER,L.; NYSTROM,S. O.; ERIKSSON, O. Endotoxins in cardiopulmonary bypass. J.Thorac: Cardiovasc. Surg., 100:777-80, 1990.

12. ROSLANSKY, P.F.; DAWSON, M.E.; NOVITSKY, T.J. Plastics,endotoxins, and the Limulus Amebocyte Lysate test. J. Parenter. Sci. Technol, 45: 83-7, 1991.

13. RUSH,B.F,; SORI, A. J.; MURPHY, T, F.; SMITH, S.; FLANAGA, J.J.; MACHIEDO, G. W.Endotoxemia and bacterenia during hemorrhagic shock. Ann. Surg., 207: 549-54, 1988.

14. SAWADA, Y.; FUJII, R.; IGAMI, I.; KAWAI, A.; KAMIKI, T.; NIWA, M. Removal of endotoxin from 
water by microfiltration through a microporous polyethylene hollow-fiber membrane. J. Appl. Eniron. Microbiol., 51: 813-20, 1986.

15.SCHEDRINA,L.E.;BRUTKO,L. L.;NUKRINA, T. Y.Study of identifying Gran negative microorganisms as sources of bacterial pyrogens, Furmatsiya, 37: 33-6, 1988.
16. TAUB,A.; HART.F. Dtoxification of pyrogens by hydrogenperoxide in some USP injections. $J$. Am. Pharm. Assric, 37; 246-50, 1948.

17. UNITED STATES PHARMACOPEIA, 22, ed. Rockville, United States Pharmacopeial Convention, 1990. p. 1493-5.

\begin{abstract}
The current search for alternalive solvents to fluorinated products, in face of the depletion of ozone in the stratosphere calls for the development of alternative processes applicable to the manufacture of medical devices. In view of the challenge and as water is serving particularly as the choice forother ind ustrial segments, the fast macrobial prohteration in it is of concern, as it is a potencial source of endotoxins. Such a risk is inconsistent with the production of items designed for example, for use in surgical procedures in the cardio-vascular field. Thus research was undertaken for the purpose of investigating the possibility of using water as a cleansing agent for components for such products. providing that hydrogen peroxide is added. The work was carried out by inoculating water and peroxide at lovels of 0.1 , $0.25,0.5$ e $1.0 \mathrm{UE} / \mathrm{m} /$. The confimation was obtained as to the active effectiveness at a $5 \%$ concentration of hydrogen peroxide by means of analytical determination using the "in vitro" method. The effectiveness of the use of peroxide was investigated on polycarbonate injected parts designed for the manufacture of oxigenators and blood reservoirs and containated with endotoxins. The findings permit one to draw a favorable conctusion regarding the adequacy of the proposed process both biologically as well as regards the removal of impurities.
\end{abstract}

Hydrogen peroxide. Endotoxins. Pyrogens. Equipment contamination, prevention \& control. 